\title{
Adherence to a Mediterranean diet in Morocco and its correlates: cross-sectional analysis of a sample of the adult Moroccan population
}

\author{
Karima El Rhazi ${ }^{1 *}$, Chakib Nejjari ${ }^{1}$, Dora Romaguera ${ }^{2}$, Catherine Feart ${ }^{3,4}$, Majdouline Obtel $^{1}$, Ahmed Zidouh ${ }^{5}$, \\ Rachid Bekkali ${ }^{5}$ and Pascale Barberger Gateau ${ }^{3,4}$
}

\begin{abstract}
Background: Dietary habits in Morocco are changing and the causes are not well understood. This study aimed to analyse socio-demographic factors associated with adherence to the Mediterranean diet (MeDi) in a national random sample of the adult Moroccan population.

Methods: The data collected in this cross-sectional survey included socio-demographic factors and a food frequency questionnaire. MeDi adherence was assessed in 2214 individuals with complete dietary data. MeDi adherence was measured according to a simplified MeDi score based on the weekly frequency of intake of eight food groups (vegetables, legumes, fruits, cereal or potatoes, fish, red meat, dairy products and olive oil) with the use of the sex specific medians of the sample as cut-offs. A value of 0 or 1 was assigned to consumption of each component according to its presumed detrimental or beneficial effect on health. Logistic regression was used to estimate the association between MeDi adherence (low score 1-4 vs. high 5-8) and other factors.

Results: Mean age of the sample was 41.4 (standard deviation 15.3) years, $45.4 \%$ were men and $29.9 \%$ had a low MeDi adherence. Married subjects (adjusted odds ratio $\mathrm{ORa}=0.68,95 \% \mathrm{Cl} 0.55-0.84$ ) were less likely to have a low MeDi adherence compared to single, divorced or widowed persons. Persons from rural areas (ORa=1.46, 95\% Cl: 1.02-2.08), were more often low MeDi adherents compared to those from urban areas. Obese persons ( $\mathrm{ORa}=1.56$, 95\% Cl: 1.16-2.11) were more prone to low MeDi adherence than normal weight individuals.

Conclusion: MeDi is far from being a universal pattern in the Moroccan population. Intervention strategies should be implemented in target groups to maintain the traditional MeDi pattern considered as the original diet in Morocco.
\end{abstract}

\section{Background}

The Mediterranean Diet (MeDi) is the dietary pattern usually consumed among the populations bordering the Mediterranean Sea. Many studies consider the MeDi as a model of healthy eating and have reported its contribution to a favorable health status, a reduced risk of many chronic diseases and a better quality of life [1-6].

Common components of the traditionally defined $\mathrm{MeDi}$ are: abundant intake of plant foods (fruits, vegetables, breads, cereals, beans, nut and seeds); olive oil as the principal source of added fat; moderate consumption

\footnotetext{
* Correspondence: elrhazikarima@gmail.com

'Department of epidemiology and Public Health, Faculty of Medicine, Fez 30000, Morocco

Full list of author information is available at the end of the article
}

of wine; low to moderate consumption of cheese, yoghurt, fish, poultry and eggs; and low consumption of red and processed meat $[1,7]$.

There is no single MeDi pattern. The dietary practices of countries bordering the Mediterranean Sea vary considerably; even within the same country, significant differences in dietary patterns exist [8]. Furthermore, many studies have showed great intake variations among Mediterranean countries and concluded that there is a Westernization of dietary habits in the Mediterranean region [9-11].

Morocco is located on the south west coast of the Mediterranean Sea. This country is undergoing a demographic and epidemiological transition. The proportion of the Moroccan population living in urban areas increased from $29.0 \%$ in 1960 to $55.1 \%$ in 2004 [12]. Life

\section{Biomed Central}


expectancy at birth increased from 47.0 years in 1962 to 72.2 years in 2007 [13]. In parallel, dietary habits, that were supposed to follow a Mediterranean pattern, have changed considerably [14,15]. During last decades, the consumption of red meat increased and was accompanied by a steadily increasing consumption of bread [15]. The causes of this nutritional transition are not well understood and it is important for policy makers to have accurate information not only about dietary shifting but also about socioeconomic and demographic factors that are related to dietary habits in Morocco.

\section{Objective}

The present study aimed to identify demographic, socioeconomic and lifestyle factors associated with adherence to a Mediterranean diet in a sample of adult Moroccan population.

\section{Methods}

The present study is a population-based cross-sectional survey carried out in May 2008.

\section{Sampling}

The target population consisted of all Moroccan subjects aged 18 years and above. The theoretical sample size was set at 3000 individuals in order to provide a precision of $2 \%$, for a $15 \%$ risk factor prevalence, $95 \%$ confidence interval and a cluster effect of 2 taking into account an anticipated $80 \%$ participation rate. The sampling technique included stratification according to geographical area (urban, rural). A cluster, which was a neighborhood in urban area and locality in rural area, of 20 households was selected at random from each of the 150 previously randomized and size proportionally selected communes. One person (men and women alternatively) aged 18 years or above was selected at random from each household of the cluster to take part in the survey. Exclusion criteria included subjects seeking medical attention due to a severe acute illness.

This study was conducted according to the guidelines laid down in the Declaration of Helsinki. It was approved by the ethics committee of Fez University Hospital Center. All subjects gave their consent before answering the survey.

\section{Questionnaire}

The questionnaire was divided into two parts. The first part included questions on demographic factors (age, sex, origin area), socio-economic status (education, monthly family income, occupation, housing category) and life style (tobacco consumption and physical activity which included usual physical activity at work, for going to and from work, and in leisure-time). The second part of the questionnaire comprised a food frequency questionnaire (FFQ) that included 38 foods and beverages commonly consumed in Morocco. Actually, ten food groups were considered (bread/cereals, rice/semolina, vegetables, legumes, fresh fruits, dairy products including milk, yogurt and cheese, red meat including veal, mutton, lamb, camel, goat..., poultry, fish, eggs), six types of beverages (milk, coffee, green and black tea, juice and soda) and five types of added fats (olive oil, argan oil, other vegetable oil, butter, cream or mayonnaise). For each participant, frequency of intake of each of the indicated food groups was reported in usual number of days of consumption per week. Eight frequency categories were proposed (less than one day/week, 1 day/week, 2/week, 3/week, 4/week, 5/week, 6/week, $7 /$ week) for each food item and beverage except for oil. For fresh fruits, both weekly frequency of intake (number of days of consumption/week) and number of portions on a typical day of intake were reported. Portion size was not assessed. For each fat type, two frequency categories were available: regular consumer (fat consumed either for dressing or cooking) vs. non consumer.

The data were collected in the subjects' homes during a personal interview carried by a trained pair (one man and one woman) including physicians and nurses. The questionnaire was administered homogeneously from Monday to Sunday. Its face validity was examined in a pilot study in 20 participants and showed that the FFQ was acceptable and understandable.

\section{Variables studied}

\section{A simplified Mediterranean-diet score}

A simplified score of MeDi adherence was constructed following an adaptation of previously described MeDi scores $[16,17]$ to take into account the available data. In the present study, computation of the simplified $\mathrm{MeDi}$ adherence score was based on the self-reported frequency of weekly intake of each food group except for fruit where the total weekly intake was calculated by multiplying the number of days of intake per week by the number of portions consumed daily. Several details about red meat consumption were reported. The frequency of consumption of high temperature cooked red meat, grilled or roasted red meat, traditional processed red meat (Khliaa and Qaddid) and modern processed red meat were added to compute the total frequency of consumption for the "red meat group" in the simplified $\mathrm{MeDi}$ score. For cereals, frequency of consumption was computed by adding the frequencies of the bread/crackers/cereal item and rice/pasta/semolina items. A value of 0 or 1 was assigned to each of these eight components (bread/cereals/riz/semolina, vegetables, fresh fruits, legumes, dairy products, red meat, fish, fat intake) using the sex-specific medians of the sample as cut-off. For components that were expected to be beneficial to 
health (vegetables, legumes, fresh fruits, cereals and fish), persons whose consumption was below the median were assigned a value of 0 , and persons whose consumption was at or above the median were assigned a value of 1. For components presumed to be detrimental for health (red meat and dairy products), persons whose consumption was below the median were assigned a value of 1, vs. 0 for the others. For fat intake, as we could not compute the mono-unsaturated fatty acid (MUFA) to saturated fatty acid ratio [16,17], we used a proxy for the computation of the simplified MeDi score. Indeed, we considered olive oil intake as the main dietary source of MUFA in Morocco in the absence of pork consumption for religious reasons. Hence, persons who consumed olive oil for dressing or for cooking were assigned a value of 1 , and 0 for non-consumers. A moderate consumption of alcohol is usually considered as a component of the traditional MeDi [16]. Given that alcohol drinking is forbidden for religious reasons, and therefore not usual or probably underreported in Moroccan population, this component was not considered for the simplified MeDi score computation. Thus, the total simplified MeDi score ranged from 0 (minimal adherence to the traditional $\mathrm{MeDi}$ ) to 8 (maximal adherence). Adherence to the MeDi was considered dichotomously: a simplified MeDi score ranging from 0 to 4 represented a low MeDi adherence whereas a simplified MeDi score ranging from 5 to 8 a high MeDi adherence. The score categories were defined so as to be close to the first tertile of the distribution of the diet score in our sample. Indeed, we made the assumption that Moroccan population still grossly adheres to MeDi and we wanted to identify people at high risk to depart from this type of diet.

\section{Other variables}

We examined monthly income of household, housing, occupation, education, marital status, gender, and place of residence (urban or rural). Income was recorded as a class variable with the following categories: $<2000$ MAD which is the minimal salary in Morocco, 2000 to 4999 MAD, and $5000 \geq$ MAD or greater (the equivalent currency exchange is: $1 \mathrm{MAD}=0.09$ Euro). Occupation was grouped into two classes: active or student, vs. retired or unemployed or housewife, the latter being used only in women. For statistical analyses, retired and unemployed individuals were grouped with housewives due to their small number and because of the difficulty to compare housewives which were all women, with other categories of occupation. Housing was classified according to criteria used previously (Moroccan Health Ministry, 2003) into four categories: luxurious or modern, new medina, old medina, poor housing or slums. Level of education was recorded into three categories: university or secondary level ( $\geq 6$ years of schooling), primary level or informal education or coranic school ([1-
6 years[), and illiterates (less than one year of schooling). Marital status was grouped into two classes: married vs single or divorced or widowed. Age was grouped into three categories $(<35 ; 35-54$ and $\geq 55$ years $)$ based on the tertile distribution of our sample.

Concerning anthropometric variables, body weight and height were measured, and body mass index (BMI) was computed as the person's weight divided by the person's size squared $(\mathrm{kg} / \mathrm{m} 2)$. BMI was used to define overweight $(\mathrm{BMI} \geq 25$ and $<30 \mathrm{~kg} / \mathrm{m} 2)$ and obesity $(\mathrm{BMI} \geq 30 \mathrm{~kg} / \mathrm{m} 2)$ according to WHO recommendations [18].

Concerning tobacco consumption, respondents were classified as current smokers (daily and occasional smokers) if they were smoking at the time of the survey; they were classified as ex-smokers if they stopped smoking during more than 3 months at the time of the survey; and they were classified as never smokers if they had never smoked in their lifetime.

Physical activity was assessed through a questionnaire which included items about moderate and vigorous activities that are performed at work and during leisure time in a usual week of the previous month. Data about transportation either by walking or cycling were also collected. For each item, number of days per week and number of minutes per day were reported. Physical activity was then defined according to WHO guidelines which recommend practicing at least 30 minutes of regular, moderate or intensive physical activity on most days [19].A person was therefore considered as active if he/she is performed at least 30 minutes of physical activity (including household activities) per day.

\section{Statistical analysis}

Food frequency consumption was described in the whole population study and in men and women separately. Sociodemographic characteristics of the sample were described according to high (simplified MeDi score 5-8) vs low (simplified MeDi score 0-4) MeDi adherence. Student's $t$-test was used for comparison of means and the chi-square tests for comparison of proportions between the two groups. Factors associated with $\mathrm{p}$ value $<0.20$ in univariate analyses were included in the multivariate logistic model. A Multivariate logistic regression analysis was used to estimate adjusted odds ratios and 95\% confidence intervals (CI) in subjects without any missing data in one or several covariates $(\mathrm{N}=2183)$. The level of significance was established at $\mathrm{p}<0.05$. Statistical analyses were carried out using Statistical Package for the Social Sciences (SPSS) v17.

\section{Results}

\section{Characteristics of the population study}

In total, out of the 3000 people selected, 2891 (96.5\%) took part in the survey, including 1430 men (49.5\%) and 
1461 women (50.5\%). People who are not included in the survey had refused to participate or were absent (3.5\%). Among the 2891, individuals with at least one missing data in at least one component of simplified MeDi adherence score $(\mathrm{N}=677,23.4 \%$ of the sample) were excluded from the computation of the score. The present study is thus based on 2214 individuals with complete dietary data. More missing data were observed in males than in females $(29.8 \%$ vs $17.4 \%$; $\mathrm{p}<0.001)$, in those of urban origin than in rural $(25.0 \%$ vs $21.6 \%$; $\mathrm{p}=0.03)$. But there was no statistical difference in mean age between subjects with complete data (41.39 years, SD 15.31) vs subjects with missing data (42.15 years,

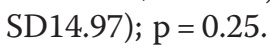

The sample description according to sex is shown in Table 1. Among the 2214 who have answered all FFQ items, $45.4 \%$ were men and $42.8 \%$ were from rural areas. Mean age was 41.4 (standard deviation, SD 15.3, median $40.0)$ years. Regarding education, $56.8 \%$ of women were illiterate vs $30.1 \%$ of men $(\mathrm{p}<0.0001)$. The proportion of participants owning less than $2000 \mathrm{MAD} /$ month seemed to be higher in men but $23.2 \%$ of the women did not know the amount of family income. For housing, $52.0 \%$ of the sample was living in slums or poor housing.

The proportion of persons considered as physically active was similar in both genders $(63.6 \%$ and $59.1 \%$ in men and women respectively). The prevalence of obesity $(B M I \geq 30 \mathrm{Kg} / \mathrm{m} 2)$ in the whole sample was $13.6 \%$ but obesity was much more frequent in women than in men $(19.8 \%$ vs $6.2 \%$; $<<0.0001)$.

\section{Food intake}

The consumption of food groups by gender is described in Table 2. Medians of food group consumption were similar in men and women except for dairy products which were more frequently consumed by women. The daily food pattern consisted of cereals and vegetables. Fresh fruits were consumed about three days/week. Red meat was consumed twice a week in median. About one half of the sample consumed fish and legume once a week. Olive oil and other vegetable oils were the main sources of fat either for cooking or dressing.

\section{Simplified Mediterranean diet adherence score}

The simplified MeDi score ranged from 1 to 8, with 31 persons in the extreme values [1,8]; $29.9 \%$ had a simplified MeDi score lower than 5. The mean simplified MeDi score was 5.1 (SD 1.2).

As expected, greater $\mathrm{MeDi}$ adherence was characterized by higher intake of vegetables, fresh fruits, legumes, cereals, fish and olive oil and by lower intake of red meat and dairy products (Table 2 ).

The associations between demographic and socio economic factors and MeDi adherence are shown in Table 3.
Table 1 Main demographic and socioeconomic characteristics according to gender

\begin{tabular}{|c|c|c|c|c|}
\hline & All population & Women & Men & $p$ \\
\hline \multicolumn{5}{|l|}{ Place of residence } \\
\hline$N$ & 2214 & 1208 & 1006 & \\
\hline Rural area & 42.8 & 40.8 & 45.2 & 0.03 \\
\hline Urban area & 57.2 & 59.2 & 54.8 & \\
\hline \multicolumn{5}{|l|}{ Age groups (years) } \\
\hline$N$ & 2212 & 1206 & 1006 & \\
\hline$<35$ & 38.1 & 43.0 & 32.3 & $<0.0001$ \\
\hline $35-49$ & 32.5 & 34.7 & 29.8 & \\
\hline$\geq 50$ & 29.4 & 22.3 & 37.9 & \\
\hline \multicolumn{5}{|l|}{ Marital status } \\
\hline$N$ & 2193 & 1194 & 999 & \\
\hline Single/Divorced/widowed & 31.5 & 34.8 & 27.5 & $<0.0001$ \\
\hline Married & 68.5 & 65.2 & 72.5 & \\
\hline \multicolumn{5}{|l|}{ Education } \\
\hline$N$ & 2204 & 1203 & 1001 & \\
\hline Illiterate & 44.6 & 56.8 & 30.0 & $<0.0001$ \\
\hline$<6$ years & 29.2 & 21.9 & 37.8 & \\
\hline$\geq 6$ years & 26.2 & 21.3 & 32.2 & \\
\hline \multicolumn{5}{|l|}{ Occupation } \\
\hline$N$ & 2186 & 1186 & 1000 & \\
\hline Active/student & 45.7 & 18.0 & 78.5 & $<0.0001$ \\
\hline Retired/unemployed/Housewife & 54.3 & 82.0 & 21.5 & \\
\hline \multicolumn{5}{|l|}{ Average family income (MAD) } \\
\hline$N$ & 2108 & 1123 & 985 & \\
\hline$<2000$ & 52.2 & 44.6 & 60.9 & $<0.0001$ \\
\hline 2000 à 4999 & 25.7 & 24.2 & 27.4 & \\
\hline$\geq 5000$ & 08.9 & 08.0 & 09.9 & \\
\hline Don't know & 13.2 & 23.2 & 01.8 & \\
\hline \multicolumn{5}{|l|}{ Housing } \\
\hline$N$ & 2214 & 1208 & 1006 & \\
\hline Luxurious or modern & 13.6 & 15.3 & 11.4 & 0.04 \\
\hline New medina & 15.4 & 15.5 & 15.2 & \\
\hline Old medina & 19.0 & 18.0 & 20.5 & \\
\hline Poor housing or slums & 52.0 & 51.2 & 52.9 & \\
\hline Tobacco consumption & & & & $<0.001$ \\
\hline Current smoker & 15.9 & 0.7 & 30.1 & \\
\hline Ex-smoker & 9.1 & 0.5 & 17.1 & \\
\hline Never smoker & 75.1 & 98.7 & 52.8 & \\
\hline \multicolumn{5}{|l|}{ Physical activity $>=30 \mathrm{~min} /$ day } \\
\hline$N$ & 2032 & 1134 & 898 & \\
\hline Yes & 61.6 & 59.1 & 63.6 & 00.040 \\
\hline
\end{tabular}


Table 1 Main demographic and socioeconomic characteristics according to gender (Continued)

\begin{tabular}{lccl}
\hline BMI class $(\mathbf{K g} / \mathbf{m} \mathbf{2})$ & 2204 & 1201 & 1003 \\
$\boldsymbol{N}$ & 56.3 & 47.4 & $67.0<0.0001$ \\
$<25$ & 30.1 & 32.8 & 26.8 \\
$25-29.9$ & 13.6 & 19.8 & 6.2 \\
$\geq 30$ & & \\
\hline
\end{tabular}

Sample of the adult Moroccan population, 2008.

There was no significant association between MeDi adherence and age, gender, education, income, occupation and physical activity. However, low MeDi adherence was associated with being single, divorced or widowed. It was also and surprisingly strongly associated with rural living $(\mathrm{p}=0.002)$. According to housing category, new and old medina residents were more likely to follow a MeDi than residents in luxurious or modern housing or those living in poor housing. A post-hoc pairwise test showed a significant difference between old medina and both luxurious or modern housing and poor housing or slums. The association with BMI was of borderline significance, with obese individuals tending to have lower MeDi adherence.

When entering all the variables associated with $\mathrm{MeDi}$ adherence at $\mathrm{p}<0.20$ in a multivariate logistic regression model (Table 4), the factors significantly and independently associated with lower MeDi adherence were rural origin, being single or divorced or widowed, luxurious or modern housing and being obese.

Table 2 Food consumption according to MeDit adherence among a sample of the adult Moroccan population, 2008

\begin{tabular}{|c|c|c|c|c|}
\hline \multirow[t]{2}{*}{ MeDi† adherence } & \multicolumn{2}{|c|}{ Low (1-4) N= 662} & \multicolumn{2}{|c|}{ High $(5-8) N=1552$} \\
\hline & Male & Female & Male & Female \\
\hline Food categories & m (SD) & $\mathrm{m}(\mathrm{SD})$ & m (SD) & $\mathrm{m}(\mathrm{SD})$ \\
\hline Bread/rice/potatoes/pasta* & $9.6(2.2)$ & $9.5(2.3)$ & $11.0(2.3)$ & $10.9(2.4)$ \\
\hline Dairy products* & $3.8(4.7)$ & $6.4(5.6)$ & $4.0(4.6)$ & $5.6(5.7)$ \\
\hline Vegetables* & $5.3(2.0)$ & $6.4(1.5)$ & $6.2(1.6)$ & $6.8(0.7)$ \\
\hline Legumes* & $0.9(1.2)$ & $0.6(1.0)$ & $1.6(1.1)$ & $1.3(1.1)$ \\
\hline Red meat* & $02.9(2.6)$ & $3.8(3.1)$ & $2.5(2.7)$ & $2.8(3.0)$ \\
\hline Fish* $^{*}$ & $1.2(1.6)$ & $1.1(1.5)$ & $1.5(1.3)$ & $1.6(1.6)$ \\
\hline Fruits** & $4.1(6.5)$ & $5.0(6.5)$ & $5.4(5.9)$ & $6.3(6.3)$ \\
\hline Olive oil (\%) & 70.0 & 59.7 & 89.3 & 86.9 \\
\hline
\end{tabular}

All $P$ values $<0.05$ for $t$-test for Equality of means or for the Chi2 test according to gender among categories of simplified MeDi score.

${ }^{*}$ Number of days of usual consumption per week, ${ }^{* *}$ Number of servings per week.

† Mediterranean Diet.
Table 3 Characteristics by categories of MeDi adherence

\begin{tabular}{|c|c|c|c|c|}
\hline & & $\begin{array}{r}\text { Simplified } \\
\text { cat }\end{array}$ & $\begin{array}{l}\text { leDit score } \\
\text { jory }\end{array}$ & \\
\hline & $\mathbf{N}$ & Low (1-4) & High (5-8) & $p$ \\
\hline Place of residence & & & & 0.002 \\
\hline Urban & 1266 & 27.3 & 72.7 & \\
\hline Rural & 948 & 33.3 & 66.7 & \\
\hline Gender & & & & 0.13 \\
\hline Women & 1208 & 28.6 & 71.4 & \\
\hline Men & 1006 & 31.5 & 68.5 & \\
\hline Age group & & & & 0.80 \\
\hline$<35$ years & 843 & 30.4 & 69.6 & \\
\hline $35-49$ years & 718 & 29.5 & 70.5 & \\
\hline$\geq 50$ years & 651 & 29.8 & 70.2 & \\
\hline Marital status & & & & 0.007 \\
\hline Single/divorced/widowed & 691 & 34.0 & 66.0 & \\
\hline Married & 1502 & 28.4 & 71.6 & \\
\hline Education & & & & 0.35 \\
\hline Illiterate & 984 & 31.0 & 69.0 & \\
\hline$<6$ years & 642 & 27.7 & 72.3 & \\
\hline$\geq 6$ years & 578 & 30.4 & 69.6 & \\
\hline Average family income ( $N$ & & & & 0.72 \\
\hline$<2000$ MAD & 1101 & 28.5 & 71.5 & \\
\hline $2000-4999$ & 541 & 28.8 & 71.2 & \\
\hline$\geq 5000$ & 188 & 31.4 & 68.6 & \\
\hline Occupation & & & & 0.18 \\
\hline Active/student & 999 & 31.1 & 68.9 & \\
\hline Retired/unemployed/House & el178 & 28.5 & 71.5 & \\
\hline Housing & & & & 0.002 \\
\hline Luxurious or modern & 300 & 33.7 & 66.3 & \\
\hline New medina & 340 & 26.5 & 73.5 & \\
\hline Old medina & 423 & 23.6 & 76.4 & \\
\hline Poor housing or slums & 1151 & 32.2 & 67.8 & \\
\hline Tobacco consumption & & & & 0.07 \\
\hline Current smoker & 290 & 66.2 & 33.8 & \\
\hline Ex-smoker & 185 & 65.4 & 34.6 & \\
\hline Never smoker & 1632 & 71.3 & 28.7 & \\
\hline $\begin{array}{l}\text { Physical activity ( } \geq 30 \\
\text { min/day) }\end{array}$ & & & & 0.34 \\
\hline Yes & 1252 & 31.0 & 69.0 & \\
\hline No & 780 & 29.0 & 71.0 & \\
\hline Class BMI (Kg/m2) & & & & 0.07 \\
\hline$<25$ & 1241 & 30.1 & 69.9 & \\
\hline $25-29.9$ & 663 & 27.1 & 72.9 & \\
\hline$\geq 30$ & 300 & 34.3 & 65.7 & \\
\hline
\end{tabular}

Sample of the adult Moroccan population, 2008 † Mediterranean Diet. 
Table 4 Multivariate logistic regression analysis of factors associated with low MeDi adherence (score 1-4)

\begin{tabular}{|c|c|c|c|}
\hline & Adjusted OR & $95 \% \mathrm{Cl}$ & p \\
\hline Gender & & & 0.37 \\
\hline Women & 0.88 & $0.67-1.16$ & \\
\hline Men & 1 & & \\
\hline Place of residence & & & 0.04 \\
\hline Rural & 1.46 & $1.02-2.08$ & \\
\hline Urban & 1 & & \\
\hline Marital status & & & $<0.001$ \\
\hline Married & 0.68 & $0.55-0.84$ & \\
\hline Single/Divorced/Widowed & 1 & & \\
\hline Housing & & & 0.03 \\
\hline Luxurious or modern & 1.66 & $1.18-2.33$ & 0.004 \\
\hline New medina & 1.15 & $0.82-1.63$ & 0.42 \\
\hline Poor housing or slums & 1.14 & $0.77-1.71$ & 0.51 \\
\hline Old medina & 1 & & \\
\hline Tobacco consumption & & & 0.14 \\
\hline Current smoker & 1.23 & $0.91-1.67$ & 0.18 \\
\hline Ex-smoker & 1.38 & $0.97-1.97$ & 0.08 \\
\hline Never smoker & 1 & & \\
\hline BMI class (Kg/m2) & & & 0.006 \\
\hline$\geq 30$ & 1.56 & $1.16-2.11$ & 0.003 \\
\hline $25-29.9$ & 0.96 & $0.76-1.20$ & 0.70 \\
\hline$<25$ & 1 & & \\
\hline Occupation & & & 0.70 \\
\hline Active/student & 1.05 & $0.82-1.34$ & \\
\hline Retired/unemployed/Housewife & 1 & & \\
\hline
\end{tabular}

Sample of adult Moroccan population without missing data, 2008. $(\mathrm{N}=2183)$ OR : Odds Ratio, $\mathrm{Cl}$ : Confidence Interval.

\section{Discussion}

The present study described the patterns of the MeDi in a sample of the adult Moroccan population and its association with socioeconomic and lifestyle characteristics. Our results show that correlates of MeDi adherence are different from those observed in other Mediterranean countries.

Indeed, contrarily to other studies [20-22], we found no association between age and $\mathrm{MeDi}$ adherence. In Mediterranean countries, especially those that are undergoing a nutritional transition, it is believed that younger people are more likely to adopt western dietary patterns. However, our study doesn't support this hypothesis and this may be related to the beginning stage of the nutritional transition in Morocco. It may also be due to that female participants were younger and at the same time adhered more to MeDi. Therefore, younger subjects who were male (thus adhere less to $\mathrm{MeDi}$ ) might not be well represented in the study population, leading to an overestimation of adherence in younger subjects. Nevertheless, our sample did not include children and adolescents under age 18, who are more prone to adopt this kind of dietary behavior.

We did not find significant differences in MeDi adherence according to either average family income or education. The same results were found in other Mediterranean countries [23,24]. Conversely, other studies showed a significant association between a healthier dietary pattern and both high education and income levels [25-27]. However, associations were found with housing categories in our study. In the new and old medina which still contains traditional houses, people are still keeping their traditional lifestyle which is maintained by availability of plants food, and their cheaper price. For people living in slums or poor housing, most of which are located in rural areas (results non shown), who are more likely living far away from markets, the low availability of food variety and the many years of drought that made them unable to grow foods in their gardens, could be an explanation for this departure from traditional MeDi.

Similarly, single, widowed and divorced persons tended to choose this westernized type of food more frequently than married ones, who seem more likely to maintain the traditional dietary habits in Morocco. This may be explained in part because married subjects eat more often regularly in family due to social obligations and share meals that are still prepared according to the traditional lifestyle.

Interestingly, higher BMI was positively associated with the lower MeDi adherence, which may be viewed as a consequence rather than a cause of the nutritional transition. The ATTICA study had already found a similar association in a Greek population [28,29]. Nevertheless, causality between obesity and the MeDi adherence cannot be drawn because of the cross-sectional design of the present study.

Many studies $[16,30]$ showed that the presence of one or more cardiovascular risk factors such as hypertension, hypercholesterolemia and diabetes, is linked to a lower adherence to the simplified MeDi [29,31]. Unfortunately, information about these cardiovascular risk factors was not available in this study. But some previous Moroccan data have shown their high prevalence [32]. This may be partly explained by departure from traditional $\mathrm{MeDi}$ in Moroccan population.

The main limitation of this study could be due to selfreported food consumption. We used a FFQ to describe the dietary profile of the Moroccan population. Food consumption was not assessed with high accuracy and people might have overestimated the consumption of healthy nutrients and food items like vegetables, fruit or cereals, typical components of the $\mathrm{MeDi}$ and underestimated the 
consumption of unhealthy nutrients and food items like red meat and some fats. Moreover, as quantities of foods were not available, we could not neither adjust for total energy intake nor calculate the MeDi adherence score following the same steps as presented elsewhere $[16,17]$ but only a simplified score. Furthermore, there was a lack of information regarding traditional CVD risk factors, such as hypertension, diabetes mellitus and hypercholesterolaemia in the study. This may explain some discordant results. Indeed, in poor housings or slums better adherence to a MeDi in terms of food choices may be counterbalanced by insufficient quantities of nutrients and low total energy intake. Another limitation is the crosssectional design of our study which did not allow the identification of individuals who shifted from a traditional to a western diet. The cross-sectional design also does not permit to interpret as causal the direction of the observed association between lower $\mathrm{MeDi}$ adherence and obesity. Nevertheless, this study has several strengths. It was conducted in a large national population sample. Participants answered a detailed questionnaire and were especially motivated by trained interviewers to answer correctly the questions without causing misclassification. The results give for the first time a description of the adherence to a $\mathrm{MeDi}$ in the Moroccan population and its correlates taking into account the seasonality of consumption since the FFQ asked about dietary habits in the previous year. This information could prove useful, particularly when no other type of comparable data are available, in the formulation of dietary guidelines, and in public health initiatives involving nutrition policies and their implementation.

\section{Conclusion}

The present study demonstrates that the MeDi is far from being a universal pattern in the Moroccan population. Adherence to a MeDi is often lost independently of age and education, especially in rural areas, among persons living alone and in those living in luxurious housing. These groups should be targeted in intervention strategies to stop the nutritional transition and to maintain the traditional MeDi pattern considered as the original diet in Morocco.

\section{Competing interests}

P. Barberger-Gateau has received fees or support for conferences from Danone, Lesieur and Aprifel, and research grants from Lesieur and Danone.

\section{Author contributions}

KE has contributed to conception and design, acquisition of data, analysis and interpretation of data and have been involved in drafting the manuscript; CN has contributed to conception and design, interpretation of data, have been involved in revising the manuscript critically and have given final approval of the version to be published. DR has been involved in drafting the manuscript CF has been involved in drafting the manuscript and have given final approval of the version to be published. MO has made substantial contributions to conception and design of data. AZ has contributed to conception and design of data. RB has contributed to conception and design of data. PBG has been involved in drafting the manuscript, revising it critically for important intellectual content and has given final approval of the version to be published. All authors read and approved the manuscript.

\section{Acknowledgements}

This study was funded by "Association Lalla Salma de Lutte contre le Cancer - Maroc".

\section{Author details}

${ }^{1}$ Department of epidemiology and Public Health, Faculty of Medicine, Fez 30000, Morocco. ${ }^{2}$ Department of Epidemiology and Biostatistics, School of Public Health, Imperial College London, London W2 1PG, UK. ${ }^{3}$ Inserm, U897, Bordeaux F-33076, France. ${ }^{4}$ Université Bordeaux Segalen, Bordeaux F-33076, France. ${ }^{5}$ Association Lalla Salma de Lutte Contre le cancer, Rabat 10000, Morocco.

Received: 17 January 2012 Accepted: 2 May 2012

Published: 11 May 2012

\section{References}

1. Willett WC, Sacks F, Trichopoulou A, Drescher G, Ferro-Luzzi A, Helsing E, Trichopoulos D: Mediterranean diet pyramid: a cultural model for healthy eating. Am J Clin Nutr 1995, 61(Suppl 6):S1402-S1406.

2. Serra-Majem L, Roman B, Estruch R: Scientific evidence of interventions using the Mediterranean diet: a systematic review. Nutr Rev 2006, 64 (Suppl 2 Pt 2):S27-S47.

3. Sofi F, Cesari F, Abbate R, Gensini GF, Casini A: Adherence to Mediterranean diet and health status: meta-analysis. BMJ 2008, 337:a1344.

4. Simopoulos AP: The Mediterranean diets: what is so special about the diet of Greece? The scientific evidence. J Nutr 2001, 131(Suppl 11):3065S3073 S.

5. Trichopoulou A, Lagiou P, Kuper H, Trichopoulos D: Cancer and Mediterranean dietary traditions. Cancer Epidemiol Biomarkers Prev 2000, 9:869-873.

6. Feart C, Samieri C, Barberger-Gateau P: Mediterranean diet and cognitive function in older adults. Curr Opin Clin Nutr Metab Care 2010, 13(Suppl 1):14-18.

7. Trichopoulou A, Lagiou P: Healthy traditional Mediterranean diet: an expression of culture, history and lifestyle. Nutr Rev 1997, 55(Suppl 11 Pt 1):383-389.

8. Sofi F: The Mediterranean diet revisited: evidence of its effectiveness grows. Curr Opin Cardiol 2009, 24(Suppl 5):442-446.

9. Karamanos B, Thanopoulou A, Angelico F, Assaad-Khalil S, Barbato A, Del Ben M, Dimitrijevic-Sreckovic V, Djordjevic P, Gallotti C, Katsilambros N, Migdalis I, Mrabet M, Petkova M, Roussi D, Tenconi MT: Nutritional habits in the Mediterranean Basin. The macronutrient composition of diet and its relation with the traditional Mediterranean diet. Multi- centre study of the Mediterranean Group for the Study of Diabetes (MGSD). Eur J Clin Nutr 2002, 56(Suppl 10):983-991.

10. Garcia-Closas R, Berenguer A, Gonzalez CA: Changes in food supply in Mediterranean countries from 1961 to 2001. Public Health Nutr 2006, 9 (Suppl 1):53-60.

11. Tur JA, Romaguera D, Pons A: Food consumption patterns in a Mediterranean region: Does the Mediterranean diet still exist? Ann Nutr Metab 2004, 48(Suppl 3):193-201.

12. Kingdom of Morocco: Haut Commissariat au Plan: General Census of Population and Housing 2004. webcite 2012 [http://www.ondh.ma/Pdf_doc $\% 5$ CRGPH_Rapport_National.pdf ] Accessed on $7^{\text {th }}$ May.

13. Kingdom of Morocco: Ministry of Health: Santé en chiffres 2010. webcite 2012. [http://srvweb.sante.gov.ma/Publications/Etudes_enquete/Documents/ SC2011.pdf] Accessed on $7^{\text {th }}$ May.

14. Mokhtar N, Elati J, Chabir R, Bour A, Elkari K, Schlossman NP, Caballero B, Aguenaou H: Diet culture and obesity in Northern Africa. J Nutr 2001, 131 (Suppl 3):887S-892S.

15. Benjelloun S: Nutrition transition in Morocco. Public Health Nutr 2002, 5 (Suppl 1A):135-140.

16. Trichopoulou A, Costacou T, Bamia C, Trichopoulos D: Adherence to a Mediterranean diet and survival in a Greek population. N Engl J Med 2003, 348(Suppl 26):2599-2608. 
17. Trichopoulou A, Kouris-Blazos A, Wahlqvist ML, Gnardellis C, Lagiou P, Polychronopoulos E, Vassilakou T, Lipworth L, Trichopoulos D: Diet and overall survival in the elderly. BMJ 1995, 311(Suppl 7018):1457-1460.

18. World Health Organization (WHO): Obesity. Preventing and Managing the Global epidemic. Report of WHO consultation on Obesity 3-5th June 1997. WHO Geneva [http://whqlibdoc.who.int/hq/1998/WHO_NUT_NCD_98.1 (p1-158).pdf] webcite 2011. Accessed on $7^{\text {th }}$ Mai.

19. WHO: Global Strategy on Diet, Physical Activity and Health. 2004. $p$. Resolution 2004, 55:23.

20. Sanchez-Villegas A, Martinez JA, De Irala J, Martinez-Gonzalez MA: Determinants of the adherence to an "a priori" defined Mediterranean diet pattern. Eur J Nutr 2002, 41:249-257.

21. Moreno LA, Sarría A, Popkin BM: The nutrition transition in Spain: a European Mediterranean country. Eur J Clin Nutr 2002, 56(Suppl 10):992-1003.

22. Duncan GJ, Wilkerson B, England P: Cleaning up their act: the effects of marriage and cohabitation on licit and illicit drug use. Demography 2006, 43:691-710.

23. EPIC Group in Spain: Sociodemographic differences in the pattern of adherence to the MeDi in Spanish populations. Gac Sanit 2002, 16:214-221.

24. Martinez-Gonzalez MA, Perez-Gutierrez R, Martinez-Gonzalez J, Garcia-Martin $\mathrm{M}$, Bueno-Cabanillas A: Dietary intake of some food items in smokers and non-smokers in a Mediterranean population. Eur J Public Health 1997, 7:40-44.

25. Katsarou A, Tyrovolas S, Psaltopoulou T, Zeimbekis A, Tsakountakis N Bountziouka V, Gotsis E, Metallinos G, Polychronopoulos E, Lionis C, Panagiotakos D: Socio-economic status, place of residence and dietary habits among the elderly: the Mediterranean islands study. Public Health Nutr 2010, 31:1-8 [Epub ahead of print].

26. Mullie $\mathrm{P}$, Clarys $\mathrm{P}$, Hulens M: Dietary patterns and socioeconomic position. Eur J Clin Nutr 2010, 64(Suppl 3):231-238.

27. Panagiotakos DB, Pitsavos C, Chrysohoou C, Vlismas K, Skoumas Y, Palliou K, Stefanadis C: Dietary habits mediate the relationship between socioeconomic status and CVD factors among healthy adults: the ATTICA study. Public Health Nutr 2008, 11(Suppl 12):1342-1349.

28. Panagiotakos DB, Chrysohoou C, Pitsavos C, Stefanadis C: Association between the prevalence of obesity and adherence to the Mediterranean diet: the ATTICA study. Nutrition 2006, 22(Suppl 5):449-456.

29. Tzima N, Pitsavos C, Panagiotakos DB, Skoumas J, Zampelas A, Chrysohoou C, Stefanadis Christodoulos: Mediterranean diet and insulin sensitivity, lipid profile and blood pressure levels, in overweight and obese people; the Attica study. Lipids Health Dis 2007, 6:22.

30. Gouveri ET, Tzavara C, Drakopanagiotakis F, Tsaoussoglou M, Marakomichelakis GE, Tountas Y, Diamantopoulos EJ: Mediterranean diet and metabolic syndrome in an urban population: the Athens Study. Nutr Clin Pract 2011, 26(Suppl 5):598-606.

31. Vlismas K, Panagiotakos DB, Pitsavos C, Chrysohoou C, Skoumas Y, Stavrinos $V$, Stefanadis C: The role of dietary and socioeconomic status assessment on the predictive ability of the HellenicSCORE. Hellenic J Cardiol 2011, 52:391-398

32. Tazi MA, Abir-Khalil S, Chaouki N, Cherqaoui S, Lahmouz F, Srairi JE, Mahjour $\mathrm{J}$ : Prevalence of the main cardiovascular risk factors in Morocco: results of a National Survey, 2000. J Hypertens 2003, 21(Suppl 5):897-903.

doi:10.1186/1471-2458-12-345

Cite this article as: El Rhazi et al:: Adherence to a Mediterranean diet in Morocco and its correlates: cross-sectional analysis of a sample of the adult Moroccan population. BMC Public Health 2012 12:345.

\section{Submit your next manuscript to BioMed Central and take full advantage of:}

- Convenient online submission

- Thorough peer review

- No space constraints or color figure charges

- Immediate publication on acceptance

- Inclusion in PubMed, CAS, Scopus and Google Scholar

- Research which is freely available for redistribution 